\title{
Inactivation of $G_{i}$ Proteins by Pertussis Toxin Diminishes the Effectiveness of Adrenergic Stimuli in Conduit Arteries from Spontaneously Hypertensive Rats
}

\author{
A. ZEMANČÍKOVÁ, J. TÖRÖK, J. ZICHA ${ }^{1}$, J. KUNEŠ ${ }^{1}$ \\ Institute of Normal and Pathological Physiology, Centrum of Excellence for Cardiovascular \\ Research, Slovak Academy of Sciences, Bratislava, Slovak Republic and ${ }^{1}$ Cardiovascular Research \\ Center, Institute of Physiology AS CR, Prague, Czech Republic
}

Received November 13, 2007

Accepted November 30, 2007

\begin{abstract}
Summary
Treatment with pertussis toxin (PTX) which eliminates the activity of $G_{i}$ proteins effectively reduces blood pressure (BP) and vascular resistance in spontaneously hypertensive rats (SHR). In this study we have compared the functional characteristics of isolated arteries from SHR with and without PTX-treatment $(10 \mu \mathrm{g} / \mathrm{kg}$ i.v., $48 \mathrm{~h}$ before the experiment). Rings of thoracic aorta, superior mesenteric artery and main pulmonary artery were studied under isometric conditions to measure the reactivity of these vessels to receptor agonists and to transmural electrical stimuli. We have found that the treatment of SHR with PTX had no effect on endothelium-dependent relaxation of thoracic aorta induced by acetylcholine. In PTX-treated SHR, the maximum contraction of mesenteric artery to exogenous noradrenaline was reduced and the dose-response curve to cumulative concentration of noradrenaline was shifted to the right. Similarly, a reduction in the magnitude of neurogenic contractions elicited by electrical stimulation of perivascular nerves was observed in the mesenteric artery from PTX-treated SHR. PTX treatment of SHR also abolished the potentiating effect of angiotensin II on neurogenic contractions of the main pulmonary artery. These results indicate that PTX treatment markedly diminishes the effectiveness of adrenergic stimuli in vasculature of SHR. This could importantly affect BP regulation in genetic hypertension.
\end{abstract}

\section{Key words}

Pertussis toxin - Hypertension - Adrenergic contractions • Conduit arteries $\bullet$ Angiotensin II $\bullet$ Gi proteins

\section{Corresponding author}

J. Török, Institute of Normal and Pathological Physiology, Slovak Academy of Sciences, Sienkewiczova 1, 81371 Bratislava, Slovak Republic. E-mail: jozef.torok@savba.sk
It has been documented that the hypertensive state in the rat is associated with an increased activity of inhibitory guanine nucleotide regulatory $\left(G_{i}\right)$ proteins in cardiovascular tissues. Enhanced activity of $\mathrm{G}_{\mathrm{i}}$ proteins preceded the development of hypertension in spontaneously hypertensive rats (SHR) (Marcil et al. 1997) and inactivation of $G_{i}$ proteins attenuated the pathological increase of blood pressure in these animals (Li and Anand-Srivastava 2002). These results indicate that the increased level of this type of $G$ proteins may be one of the factors participating in the pathogenesis of hypertension. Di Fusco and Anand-Srivastava (2000) reported that the hearts from rats with $\mathrm{N}^{\mathrm{G}}$-nitro-Larginine methyl ester (L-NAME)-induced hypertension also exhibited an enhanced expression of $\mathrm{G}_{\mathrm{i}}$ proteins. Their later results demonstrated that the expression of $G_{i}$ alpha-2 and $G_{i}$ alpha-3 proteins and their mRNA, which was enhanced in L-NAME-treated rats, was reversed by losartan treatment, which simultaneously attenuated the L-NAME-induced increase in blood pressure (Hashim and Anand-Srivastava 2004). These facts promote the idea that the overexpression of $\mathrm{G}_{\mathrm{i}}$ proteins could also accompany the induction of hypertension.

One of the possibilities how to evaluate the participation of this factor in chronic elevation of blood pressure is the elimination of $G_{i}$ protein function, i.e. a blockade of $G_{i}$ protein signaling. Inhibitory $G$ proteins are involved in signal transduction pathways of many hormones and transmitters and the well-known result of their activation is the inhibition of adenylate cyclase 
activity and reduction of cAMP production. Pertussis toxin (PTX) catalyses covalent modification of alpha subunit of $\mathrm{G}_{\mathrm{i}}$ proteins by ADP-ribosylation making it incapable of exchanging GDP for GTP, which results in attenuation of $\mathrm{G}_{\mathrm{i}}$ protein function. Several authors reported that PTX effectively reduces blood pressure in rats with spontaneous hypertension (Kost et al. 1999, Pintérová et al. 2007). Our previous experiments carried out in femoral arteries of normotensive WKY rats (Líšková et al. 2007) demonstrated that PTX pretreatment caused the attenuation of noradrenaline-induced contraction, both in the presence of endothelium or after its removal. These data also indicated that $\mathrm{G}_{\mathrm{i}}$-dependent vasoconstrictor effect of noradrenaline operate via the control of calcium influx through voltage-dependent $\mathrm{Ca}^{2+}$ channels. In the present study we are testing the hypothesis that the treatment of SHR with this toxin affects the functional characteristics of their vessels.

Male 12-week-old SHR were used, in which half of the animals was administered an intravenous injection of PTX $(10 \mu \mathrm{g} / \mathrm{kg}) 48 \mathrm{~h}$ before the experiment. We assessed the reactivity of isolated conduit arteries (thoracic aorta, superior mesenteric artery, main pulmonary artery) from control and PTX-treated SHR to various vasoactive agents under isometric conditions. Vasoconstrictor responses were elicited by noradrenaline applied cumulatively into the bathing solution, or by endogenous noradrenaline released from electrically stimulated perivascular nerve endings. In our experiments, maximal contractile response of mesenteric artery to exogenous noradrenaline was attenuated in PTX-treated SHR $\left(4.29 \pm 0.61 \mathrm{mN} / \mathrm{mm}^{2}\right)$ compared to the untreated control group $\left(7.74 \pm 1.65 \mathrm{mN} / \mathrm{mm}^{2}, \mathrm{P}<0.05\right)$ and dose-response curve to cumulative concentrations of noradrenaline was shifted to the right (Fig. 1) indicating decreased sensitivity of vascular smooth muscle to noradrenaline. Similar shift of the dose-response curve to noradrenaline was also observed in the thoracic aorta (data not shown). This decrease in sensitivity to noradrenaline results from the blockade of $G_{i}$ proteinmediated signal pathway which normally contributes to the total vasoconstrictor response to this agonist. Indeed, PTX pretreatment of WKY rats decreased noradrenalineinduced contraction of femoral arteries due to a reduction of nifedipine-sensitive $\mathrm{Ca}^{2+}$ influx (Líšková et al. 2007).

The role of $G_{i}$ proteins in adrenergic contraction is associated with $\alpha_{2}$-adrenoreceptors and this pathway leads to the entry of extracellular calcium because $\alpha_{2}$ adrenoreceptor function in the vascular smooth muscle is

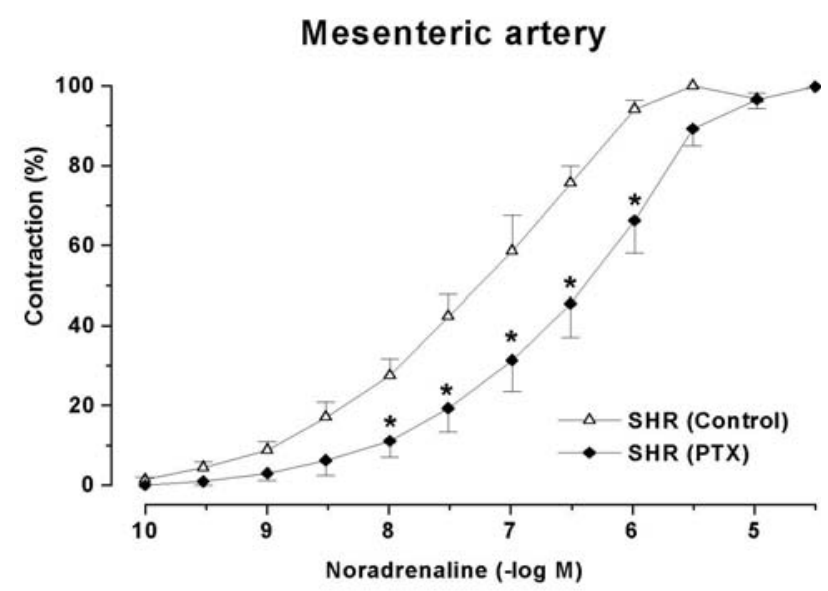

Fig. 1. Concentration-response curves for noradrenaline-induced contraction of the mesenteric artery from control SHR $(\triangle)$ and PTX-treated SHR $(\bullet) . * \mathrm{P}<0.05$ vs. control. Data are in percentage of maximal noradrenaline-induced contraction.

sensitive to calcium entry blocking agents (Cavero et al. 1983). It was found that the contractile responses to clonidine (an $\alpha_{2}$-adrenoreceptor agonist) are significantly greater in the tail arteries isolated from SHR than in those from normotensive Wistar-Kyoto rats (Weiss et al. 1984, Li and Triggle 1993). After PTX-treatment, clonidineinduced contractions were almost completely blocked, while the responses to cirazoline (an $\alpha_{1}$-adrenoreceptor agonist) were diminished only partly ( $\mathrm{Li}$ and Triggle 1993). Similar results were also obtained in vivo (Pintérová et al. 2007). The enhanced $\alpha_{2}$-adrenoreceptor component of the total constrictor response to noradrenaline in SHR could be a consequence of the increased level of $\mathrm{G}_{i}$ proteins, as was mentioned above. In our experiment, this factor was reduced by PTX, which could partially normalize the hypersensitivity of adrenergic system of SHR in this way. Similarly, the neurogenic contractions of mesenteric artery, elicited by the endogenous noradrenaline, which originated from perivascular nerves and was released during transmural electrical stimulation at various frequencies, were significantly reduced in SHR treated with PTX (Fig. 2). For example, in control SHR, stimulation at $4 \mathrm{~Hz}$ caused a contraction averaging $2.54 \pm 0.50 \mathrm{mN} / \mathrm{mm}^{2}$, while in PTX-treated SHR it was decreased to $1.17 \pm 0.24 \mathrm{mN} / \mathrm{mm}^{2}$ $(\mathrm{P}<0.05)$.

Our results have not shown any differences in acetylcholine-induced endothelium-dependent relaxation in the thoracic aorta (precontracted by $10^{-6} \mathrm{~mol} / \mathrm{l}$ phenylephrine) isolated from SHR and PTX-treated SHR. Arterial preparations obtained from both groups of 


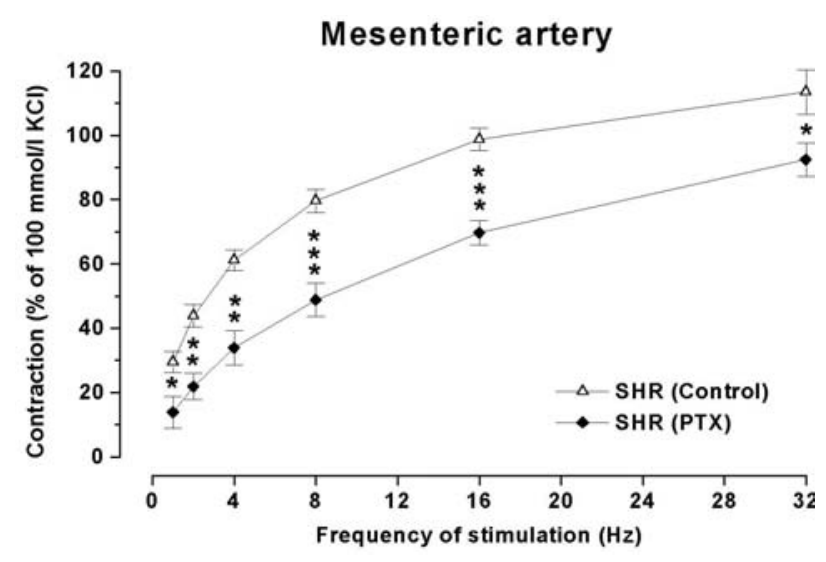

Fig. 2. Frequency-dependent contractions of the mesenteric artery from control SHR $(\triangle)$ and PTX-treated SHR $(\bullet)$. $* P<0.05$; $* * \mathrm{P}<0.01 ; * * * \mathrm{P}<0.001$ vs. control. Data are in percentage of maximal $\mathrm{KCl}$-induced contraction.

animals relaxed very effectively in response to acetylcholine indicating that PTX could not affect the NO-cGMP system in this experiment (data not shown).

In SHR, renal vasculature shows an enhanced responsiveness to angiotensin II, which is one of the factors contributing to the maintenance of high blood pressure (Li and Jackson 1989, Vyas and Jackson 1995). Pertussis toxin normalizes renovascular responses to angiotensin II, suggesting a role of altered $\mathrm{G}_{\mathrm{i}}$-signaling in the enhanced effect of this peptide on renal vascular resistance in SHR (Jackson 1994). In the present study, we have investigated the indirect effect of angiotensin II on the vascular tone of the rat main pulmonary artery, through modulation of its adrenergic responses, which were induced by the release of endogenous noradrenaline from vascular nerve endings during transmural electrical stimulation at a frequency of $4 \mathrm{~Hz}$. Neurogenic contractions were elicited under basal conditions and after the administration of angiotensin II $\left(10^{-8} \mathrm{~mol} / \mathrm{l}\right)$ into the bathing medium. Angiotensin II exerts a potentiating effect on these contractions, suggesting mainly presynaptic modulation of noradrenaline release. This action is one of the mechanisms of positive feedback between the sympathoadrenergic and renin-angiotensin system and could also play an important role in the maintenance of elevated vascular resistance in hypertension. A potentiation of noradrenergic neurotransmission by angiotensin II was found to be increased in perfused mesenteric vascular bed of genetically hypertensive rats (Kawasaki et al. 1982). In our experiments, treatment of SHR with PTX has abolished the enhancement of neurogenic contractions produced by angiotensin II, indicating that $G_{i}$ proteins

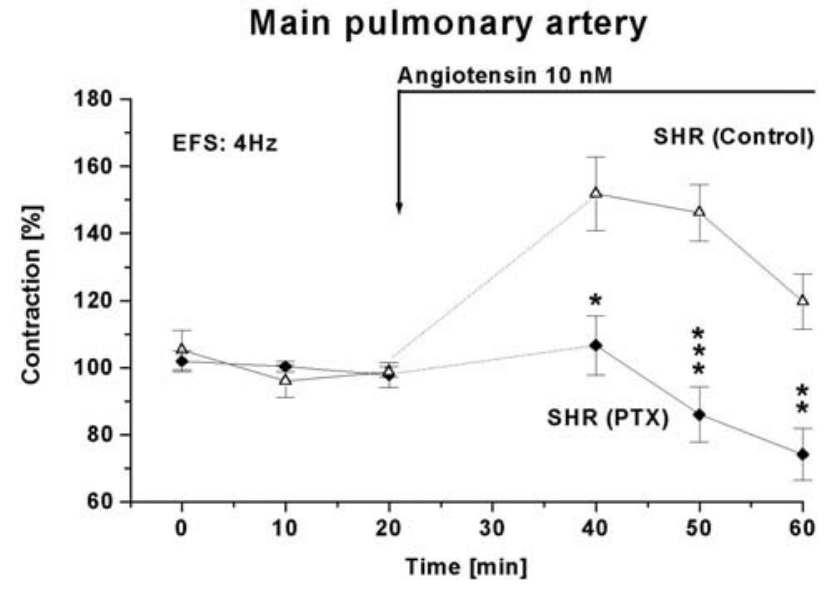

Fig. 3. Potentiating effect of angiotensin II on neurogenic contractions of the main pulmonary artery from control SHR $(\triangle)$ and PTX-treated SHR $(\diamond) . * \mathrm{P}<0.05 ; * * \mathrm{P}<0.01 ; * * * \mathrm{P}<0.001$ vs. control. Data are in percentage of contraction at a frequency of $4 \mathrm{~Hz}$ before the addition of angiotensin.

may also be involved in this process. In control SHR, preincubation of isolated main pulmonary artery with angiotensin II for $20 \mathrm{~min}$ caused an increase of neurogenic contractions by $52 \%$. In preparations obtained from SHR treated with PTX, this enhancing effect of angiotensin II on neurogenic contractions was only $7 \%$ (Fig. 3). Talaia et al. (2006) observed that the facilitation of $\left[{ }^{3} \mathrm{H}\right]$-noradrenaline release mediated by angiotensin II was blunted, when $\alpha_{2}$-adrenergic receptors were selectively blocked with yohimbine or when PTX was used. $\alpha_{2}$-adrenergic receptors are also localized on vascular nerve endings of the sympathetic system and produce autoinhibition of noradrenaline overflow. Cox et al. (2000) reported that the prejunctional facilitatory effect of angiotensin II in isolated mouse atria requires the conditions of prejunctional $\alpha_{2}$-adrenergic autoinhibition. These authors also referred about the cross-talk between $G_{i}$ protein-coupled receptors and $G_{q}$ protein-coupled receptors (presynaptic $\mathrm{AT}_{1}$ receptors for angiotensin II, in this case), which is responsible for this phenomenon. According to this hypothesis, a major part of the release-enhancing effect elicited through prejunctional $\mathrm{AT}_{1}$ receptors is due to the disruption of an ongoing $\alpha_{2}$-adrenergic receptor-triggered $G_{i}$ proteinmediated inhibition. This may serve as an explanation for the abolishing effect of PTX on the angiotensin IIinduced facilitation of neurogenic contractions observed in this experiment.

In conclusion, our results suggest that the elimination of $\mathrm{G}_{\mathrm{i}}$ proteins by PTX markedly attenuates 
the sensitivity of the noradrenergic system, which represents one of the main vasoconstrictor stimuli. This treatment is especially effective under the conditions of genetic hypertension, where increased sympathoadrenergic activity and enhanced $\mathrm{G}_{\mathrm{i}}$ protein expression were found.

\section{Conflict of Interest}

There is no conflict of interest.

\section{Acknowledgements}

Supported by VEGA grant No. 2/6150/27 as well as by 1M0510 (Cardiovascular Research Center, Prague).

\section{References}

CAVERO I, SHEPPERSON NB, LEFEVRE-BORG F, LANGER SZ: Differential inhibition of vascular smooth muscle responses to $\alpha-1$ and $\alpha-2$ adrenoceptor agonists by diltiazem and verapamil. Circ Res 52: 69-76, 1983.

COX SL, SCHELB V, TRENDELENBURG AU, STARKE K: Enhancement of noradrenaline release by angiotensin II and bradykinin in mouse atria: evidence for cross-talk between $\mathrm{G}_{\mathrm{q} / 11}$ protein- and $\mathrm{G}_{\mathrm{i} / \mathrm{o}}$ protein-coupled receptors. Br J Pharmacol 129: 1095-1102, 2000.

DI FUSCO F, ANAND-SRIVASTAVA MB: Enhanced expression of Gi proteins in non-hypertrophic hearts from rats with hypertension induced by L-NAME treatment. J Hypertens 18: 1081-1090, 2000.

HASHIM S, ANAND-SRIVASTAVA MB: Losartan-induced attenuation of blood pressure in L-NAME hypertensive rats is associated with reversal of the enhanced expression of Gi alpha proteins. J Hypertens 22: 181-190, 2004.

JACKSON EK: Pertussis toxin normalizes enhanced renovascular responses to angiotensin II in spontaneously hypertensive rats. Life Sci 54: PL445-PL450, 1994.

KAWASAKI H, CLINE WH JR, SU C: Enhanced angiotensin-mediated facilitation of adrenergic neurotransmission in spontaneously hypertensive rats. J Pharmacol Exp Ther 221: 112-116, 1982.

KOST CK JR, HERZER WA, LI PJ, JACKSON EK: Pertussis toxin-sensitive G-proteins and regulation of blood pressure in the spontaneously hypertensive rat. Clin Exp Pharmacol Physiol 26: 449-455, 1999.

LI P, JACKSON EK: Enhanced slow-pressor response to angiotensin II in spontaneously hypertensive rats. J Pharmacol Exp Ther 251: 909-921, 1989.

LI X-F, TRIGGLE CR: Effects of pertussis and cholera toxins on $\alpha$-adrenoceptor function in rat tail artery: differences in hypertension. Can J Physiol Pharmacol 71: 791-799, 1993.

LI Y, ANAND-SRIVASTAVA MB: Inactivation of enhanced expression of Gi proteins by pertussis toxin attenuates the development of high blood pressure in spontaneously hypertensive rats. Circ Res 91: 247-254, 2002.

LÍŠKOVÁ S, KUNEŠ J, ZICHA J: Nifedipine-sensitive vascular reactivity of femoral arteries in WKY: the effects of pertussis toxin pretreatment and endothelium removal. Physiol Res 56: 663-667, 2007.

MARCIL J, THIBAULT C, ANAND-SRIVASTAVA MB: Enhanced expression of Gi-protein precedes the development of blood pressure in spontaneously hypertensive rats. J Mol Cell Cardiol 29: 1009-1022, 1997.

PINTÉROVÁ M, KUNEŠ J, DOBEŠOVÁ Z, ZICHA J: The role of calcium influx and $\mathrm{G}_{\mathrm{i}}$ proteins in $\alpha_{1}$ - and $\alpha_{2}$ adrenergic vasoconstriction elicited in SHR and WKY rats. Physiol Res 56: 29P, 2007.

TALAIA C, QUEIROZ G, PINHEIRO H, MOURA D, GONÇALVES J: Involvement of G-protein beta-gamma subunits on the influence of inhibitory $\alpha_{2}$-autoreceptors on the angiotensin $\mathrm{AT}_{1}$-receptor modulation of noradrenaline release in the rat vas deferens. Neurochem Int 49: 698-707, 2006.

VYAS SJ, JACKSON EK: Angiotensin II: enhanced renal responsiveness in young genetically hypertensive rats. J Pharmacol Exp Ther 273: 768-777, 1995.

WEISS RJ, WEBB RC, SMITH CB: Comparison of $\alpha_{2}$ adrenoreceptors on arterial smooth muscle and brain homogenates from spontaneously hypertensive and Wistar-Kyoto normotensive rats. J Hypertens 2: 249-255, 1984. 